\title{
Adipofascial perforator flaps: Its role in reconstruction of soft-tissue defects of lower leg and ankle
}

\author{
Deepak Nanda, Shamendra Anand Sahu1, Durga Karki, Sanjay Kumar², Amrita Mandal \\ Department of Burns, Plastic and Maxillofacial Surgery, Safdarjung Hospital and VMMC, 'Department of Plastic and \\ Reconstructive Surgery, All India Institute of Medical Sciences, New Delhi, ${ }^{2}$ Department of Plastic Surgery, Nalanda Medical \\ College and Hospital, Patna, Bihar, India
}

Address for correspondence: Dr. Shamendra Anand Sahu, Department of Plastic and Reconstructive Surgery, All India Institute of Medical Sciences, Room No 5014c, Academic Block, Ansari Nagar, New Delhi - 110 029, India. E-mail: shamendrasahu@gmail.com

\section{ABSTRACT}

Background: Despite advances in surgical skills, adipofascial flaps are still less preferred option for coverage ofleg defect. Weevaluate the use of perforator-based adipofascial flap insmall-to-medium-sized soft-tissue defects in the lower limb. Patients and Methods: After localisation of perforators along the major axial vessels in the lower limb using handheld Doppler, adipofascial flap based on the nearest best perforator of anterior tibial artery, posterior tibial artery and peroneal artery was raised to cover soft-tissue defect in 21 patients. The flap was transposed over the defect and covered by split-skin graft. Donor site was primarily closed. Flap complications, functional and aesthetic outcomes are noted in follow-up. Results: There was partial loss of flap in five patients. After debridement and dressings, split-skin grafting was done for four patients and one patient was managed with local flap. Scar over the flap was stable with no reports of recurrent ulceration or breakdown of wound in 6-month follow-up. Four of five patients reported adequate healing of the fractured bone. Average visual analogue score was $8.24 / 10$ for appearance of donor site as evaluated by the patient. Conclusions: Perforator-based adipofascial flap is a good alternative for coverage of small-to-medium-sized soft-tissue defect of the leg, particularly over the malleolus and lower part of the leg. Use of adipofascial tissue and primary closure of the donor site causes minimal donor-site morbidity. Adipofascial perforator flap provides aesthetically superior recipient-site scar with satisfactory functional outcome.

\section{KEY WORDS}

Adipofascial flap; adipofascial perforator flap; lower leg soft-tissue defect; perforator flap; turnover flap

\section{INTRODUCTION}

he surgical planning for the lower-limb soft-tissue defects has changed significantly with the improvement in microvascular surgical concepts.

\begin{tabular}{|l|l|}
\hline \multicolumn{2}{|c|}{ Access this article online } \\
\hline Quick Response Code: & Website: \\
\hline & www.ijps.org \\
\cline { 2 - 2 } & Dol: \\
\hline
\end{tabular}

Free tissue transfer provides adequate coverage; however, contour defect at the recipient and donor site remains a significant problem. Furthermore, acquiring technical

This is an open access journal, and articles are distributed under the terms of the Creative Commons Attribution-NonCommercial-ShareAlike 4.0 License, which allows others to remix, tweak, and build upon the work non-commercially, as long as appropriate credit is given and the new creations are licensed under the identical terms.

For reprints contact: reprints@medknow.com

How to cite this article: Nanda D, Sahu SA, Karki D, Kumar S, Mandal A. Adipofascial perforator flaps: Its role in reconstruction of soft-tissue defects of lower leg and ankle. Indian J Plast Surg 2018;51:216-21. 
expertise and proper instrumentation are limitations for lesser use of this option. Therefore, local flaps still remain workhorse for coverage of soft-tissue defects of the lower leg.

Adipofascial tissue is well defined in the leg as compared to other areas of the body. They are composed of subcutaneous fat and deep fascia with reliable blood supply. Surgical plane in the leg is deep to the deep fascia. ${ }^{[1]}$ Adipofascial tissue without skin elements increases its adaptability and pliability for swift manipulation to cover soft-tissue defect of the leg.

In the early 1990s, adipofascial turnover and local transposition flaps gained some popularity with the work of Lin et al., but the past years had not seen much work on this potentially usable tissue. ${ }^{[2,3]}$ Using Doppler, adipofascial tissue based on perforator can be easily raised in the lower limb sparing its major neurovascular structures. ${ }^{[4]}$ With this modification, we have evaluated the use of adipofascial perforator flap for covering small-to-medium-sized soft-tissue defect in the lower limb.

\section{PATIENTS AND METHODS}

This is a prospective observational study. Patients of age $>18$ years with clinically small-to-medium-sized post-traumatic soft-tissue defect of the leg requiring flap cover were included in the study. Patients with systemic illnesses such as uncontrolled diabetes mellitus, atherosclerosis and peripheral vascular diseases were excluded from the study. Soft-tissue defect of 21 patients was reconstructed using perforator-based adipofascial flap between January 2012 and November 2013. Due permission was taken from institutional research and ethical committee. Written informed consent was taken from the patients.

Pre-operative localisation of the perforators was done using handheld Doppler probe of $8 \mathrm{MHz}$ along the axis of anterior tibial artery, posterior tibial artery and peroneal artery. Flap was planned on the nearest best-marked perforator as a pivot point. Previous traumatic scars, surgical scars and external fixator applied were taken into consideration while planning. The flap design was adjusted as per intraoperative location of the better adjacent perforator, i.e., bigger size or pulsating perforator was given preference over smaller non-pulsating perforator.
Patients were operated under regional anaesthesia. Dissection was done under $3.5 \times-4.5 \times$ loupe magnification. Tourniquet applied was inflated without exsanguination of the limb. It facilitates intraoperative identification of perforators as they remain filled with blood. Skin flaps were raised as planned just deep to dermis sparing only minimal adipose tissue with the skin flaps. Taking too much areolar tissue with the skin flap decreases the thickness of the adipofascial tissue to be raised as flap. Adipofascial tissue was exposed, and planned flap was duplicated over it using template considering the size of soft-tissue defect. One margin of flap was incised, and adipofascial tissue was raised in subfascial plane for localisation the perforator. Once a suitable perforator was found, dimensions of flap were confirmed or changed to the extent as required. Other margins of adipofascial flap were incised so as to island it on selected perforators. All fascial attachments around the perforator were released, and dissection around the perforator in intermuscular or intramuscular plane was done to gain additional length. After deflating tourniquet with the flap in its native position, haemostasis was achieved and viability of flap evaluated. Finally, the flap was transposed into the defect. Pivot point of perforator was rechecked to avoid kinking. In adipofascial perforator flap, a small adipofascial tissue can be raised distal to the perforator. In our cases, we have used this smaller blade either to cover the pedicle or fill the defect to improve the contour deformity. After insetting over the defect, the adipofascial flap was covered with split-thickness skin graft, and the donor area was closed primarily.

Post-operatively, the flap was monitored by colour of ooze of blood on needle prick from the fenestrations made in the skin graft. Patients were followed till healing of the wound, and at 1 month, 3 months and 6 months to assess the functional and aesthetic outcome in terms of adequate healing of the wound, any functional limitations imposed by harvesting flap, sensory abnormalities and contour deformities of the donor site.

\section{RESULTS}

Of 21 patients included in the study, 19 were male and 2 were female. The youngest patient in the cohort was 19 years and the oldest patient was 60 years of age. Aetiology and location of soft-tissue defect in the lower limb are shown in Table 1. The size of soft-tissue defect ranged from $2 \mathrm{~cm} \times 3 \mathrm{~cm}$ to $9 \mathrm{~cm} \times 4.5 \mathrm{~cm}$ in the greatest dimension.

Indian Journal of Plastic Surgery Volume 51 Issue 2 May-August 2018 
In our study, posterior tibial artery perforators were most commonly used for elevating flaps. Anterior tibial artery perforator-based flap was used in two patients [Table 2]. There was congestion of the flap in six patients in the early post-operative period. Vascularity of one flap improved after removing hematoma underneath. In other five cases, the holding sutures at the margins of the flap and of the skin bridge segment were opened up. Congestion improved but there was partial flap loss. In four patients, after debridement and dressing, split-skin grafting was done when healthy granulation tissue was formed. One patient required local transposition flap to cover the exposed tendon. Partial loss of split-skin graft over the adipofascial flap occurred in two patients who healed with regular dressings. Regarding the functional outcome, of the five patients who were having fractured tibia, four healed satisfactorily while one patient developed osteomyelitis who was lost in follow-up. These findings were confirmed on X-ray and clinical examination by concerned orthopaedic surgeon. We subjectively evaluated aesthetic appearance of donor site by the patient and resident doctor separately as per visual analogue scale (VAS) (0-10). The average patient's score was 8.24 and average doctor's score was 7.95 , but the difference between the average patient's and doctor's VAS value was statistical insignificant (one-tailed test, $P=0.09232$ ).

Table 1: Aetiology and location of the leg defect

\begin{tabular}{lc}
\hline & $\begin{array}{c}\text { Total number } \\
\text { of patients: 21 }\end{array}$ \\
\hline Aetiology of leg defect & 16 \\
Post-traumatic & 2 \\
Post-infective & 2 \\
Post-burn & 1 \\
Dehiscence after orthopaedic intervention & \\
Location of defect & 8 \\
Middle one-third of the leg & 4 \\
Lower one-third of the leg & 5 \\
Medial malleolus & 4 \\
Lateral malleolus & \\
\hline
\end{tabular}

\section{Case 1}

A 42-year-old male presented with a $9 \mathrm{~cm} \times 4.5 \mathrm{~cm}$ wound over lateral malleolus. An $18 \mathrm{~cm} \times 5 \mathrm{~cm}$ adipofascial flap based on a perforator $12.5 \mathrm{~cm}$ above the lateral malleolus was raised and transposed to cover the defect [Figure 1].

\section{Case 2}

A 42-year-old patient came with a $3 \mathrm{~cm} \times 4 \mathrm{~cm}$ post-traumatic wound over the medial malleolus of the right leg 25 days after a road traffic accident. A $25 \mathrm{~cm} \times 4.5 \mathrm{~cm}$ adipofascial flap based on posterior tibial artery perforator located $9 \mathrm{~cm}$ from the medial malleolus was harvested for wound coverage [Figure 2].

\section{Case 3}

A 48-year-old male presented with post-infective wound in the middle one-third of leg, $3 \mathrm{~cm} \times 4 \mathrm{~cm}$ in size. An $11 \mathrm{~cm} \times 4 \mathrm{~cm}$ anterior tibial artery perforator-based adipofascial flap cover was done. Both the blades of the flap were used to fill the defect. There were no post-operative complications [Figure 3].



Table 2: Location of zone of perforator used for harvesting adipofascial flap

\begin{tabular}{|c|c|c|c|c|c|}
\hline \multicolumn{2}{|c|}{ PTAP adipofascial flap } & \multicolumn{2}{|c|}{ PAP adipofascial flap } & \multicolumn{2}{|c|}{ ATAP adipofascial flap } \\
\hline $\begin{array}{l}\text { Location of } \\
\text { perforator }(\mathrm{cm})\end{array}$ & $\begin{array}{l}\text { Number } \\
\text { of patient }\end{array}$ & $\begin{array}{c}\text { Location of } \\
\text { perforator }(\mathrm{cm})\end{array}$ & $\begin{array}{l}\text { Number } \\
\text { of patient }\end{array}$ & $\begin{array}{c}\text { Location of } \\
\text { perforator }(\mathrm{cm})\end{array}$ & $\begin{array}{c}\text { Number } \\
\text { of patient }\end{array}$ \\
\hline $4-6$ & 4 & $8-10$ & 2 & 5.5 & 1 \\
\hline $6-8$ & 3 & & & & \\
\hline $8-10$ & 5 & & & & \\
\hline $10-12$ & 1 & $12-14$ & 2 & 21 & 1 \\
\hline $12-14$ & 0 & & & & \\
\hline $14-16$ & 2 & & & & \\
\hline Total & 15 & & 4 & & 2 \\
\hline
\end{tabular}

Distances are from lower reference points: Tip of malleoli and mid-malleolar point. PTAP: Posterior tibial artery perforator, PAP: Peroneal artery perforator, ATAP: Anterior tibial artery perforator 


\section{DISCUSSION}

Soft-tissue reconstruction of the leg should be durable, aesthetically acceptable and with minimal donor-site morbidity. The operative procedure should also be technically easy. Adipofascial tissue of the leg raised as perforator flap can have wide applications to provide durable cover for soft-tissue defect of the leg and minimal donor-site morbidity.

Providing ideal soft-tissue coverage is strenuous work for reconstructive surgeons which has led to continuous refinement of surgical options and evolution of new techniques. Microvascular tissue transfer is suitable option for large and complicated leg defects, but they still are not suitable for small-to-medium-sized defects, especially around medial malleolus and lateral malleolus. Furthermore, some patients are not suitable candidates for free tissue transfer because of existing comorbidities, and proper instrumentation with adequate microsurgical skills is prerequisites for it. The rationale behind the fasciocutaneous flap is robust blood supply of the deep fascia. Bulkiness at the recipient site, donor-site disfigurement, limitation in reach and mobility of the bulky flap are the major limitations. Oedema, inflammation and scar in the surrounding area of the defect preclude the use of local fasciocutaneous flaps. Local muscle and musculocutaneous flaps are reliable option for coverage but are associated with significant donor-site deformity and may cause functional deficits. Furthermore, they are less pliable which limits their reach and rotational capacity.

We have evaluated adipofascial perforator flap for its feasibility to cover small-to-medium-sized soft-tissue defect of the leg, its outcomes in terms of flap

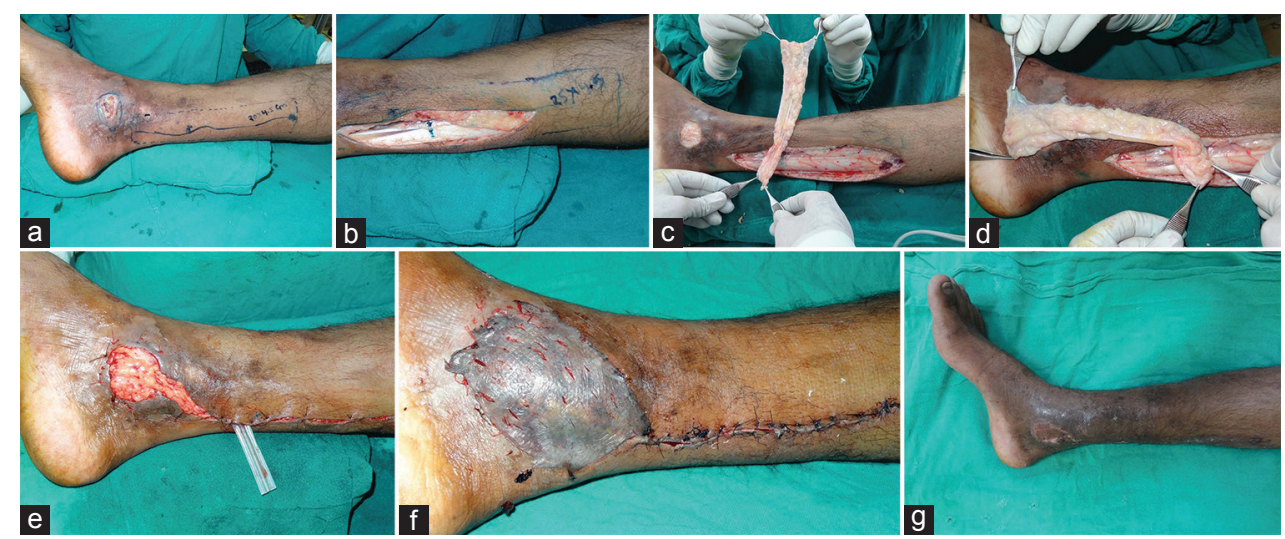

Figure 2: (a) Image showing the right limb of patient with soft-tissue defect over medial malleolus and planned flap of $20 \mathrm{~cm} \times 4.5 \mathrm{~cm}$ in size. (b) Flap size readjusted to $25 \mathrm{~cm} \times 4.5 \mathrm{~cm}$ as per intraoperative location of perforator. (c) Adipofascial flap raised on posterior tibial artery perforator. (d) Image showing $180^{\circ}$ rotation of adipofascial flap to cover medial malleolus defect. (e) Insetting of the adipofascial flap. (f) Adipofascial tissue covered with split-skin graft. (g) Follow-up after 3 weeks showing adequate healing of donor and recipient site

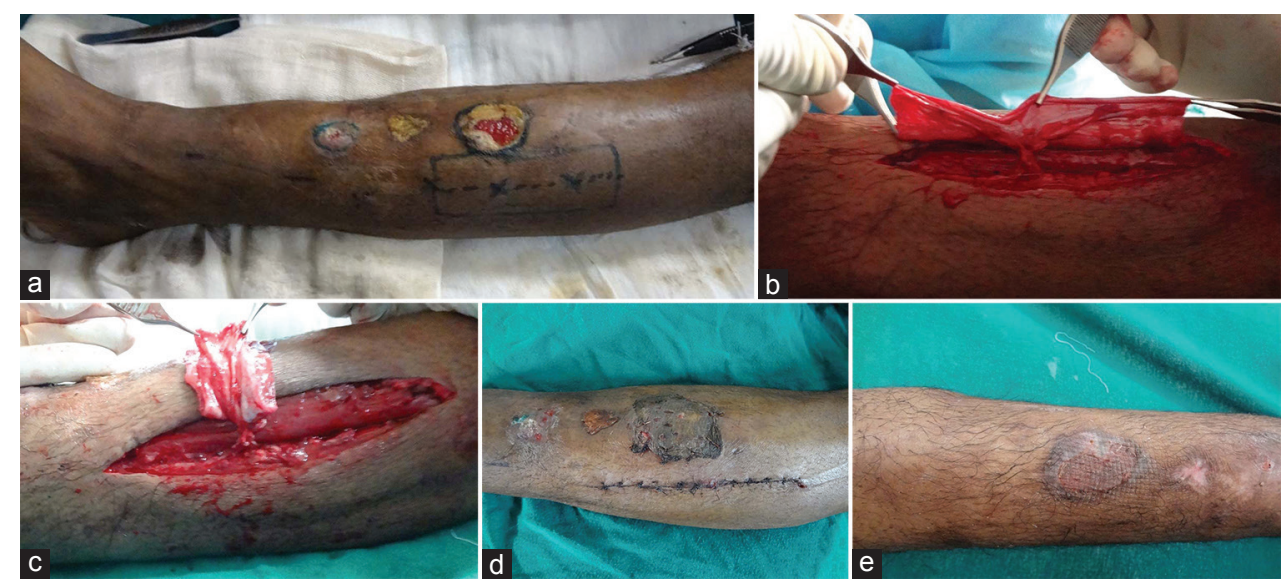

Figure 3: (a) Left lower-limb soft-tissue defect of patient's tibia covered with scab and granulation tissue. (b) Adipofascial flap raised on anterior tibial artery perforator. (c) Both leaves of the flap are used to fill the defect. (d) Adipofascial flap covered with split-skin graft and donor-site primarily closed. (e) Follow-up after 2 weeks showing adequate healing of flap and donor site 
complications, functional outcome and aesthetic donor-site appearance.

Adipofascial perforator flap leaves minimal scar and no major sensory disturbances at the donor site. Unlike fasciocutaneous flaps, adipofascial tissue is truly plastic in nature because it can be easily moulded and contoured according to the size and depth of defect [Figure 1].

There was no report of flap necrosis or venous congestion when Lin et al. used distally based adipofascial turned down and transposition flap from medial side of the leg to cover soft-tissue defect over the tibia in five patients. ${ }^{[2]}$ Distally-based medial, lateral and superficial sural artery-based adipofascial flap was used to cover medial and lateral malleolar soft-tissue defect in 12 patients, and all flaps were reported to survive well. ${ }^{[5]}$ The author reported flap tip necrosis in one of 12 patients when distally based medial adipofascial flap was used to cover soft-tissue defect in the lower half of the leg. Complete loss of flap was not a complication in our patients also. In our cohort, there was partial loss of flap in five patients due to venous congestion. One drawback of all adipofascial flaps is venous congestion. Veins are more prone to torsion than arteries. The congestion can be temporary with stabilisation of flow after some time. This may lead to necrosis of tip or loss of superficial tissue. True insufficiency resulting in necrosis can occur in few cases. Worsening congestion may require derotation of the flap or venous supercharging. ${ }^{[6]}$

On thorough search of literature, we could not find safe size of adipofascial tissue that can be raised as flap. In our study, we have successfully used $25 \mathrm{~cm} \times 4.5 \mathrm{~cm}$ posterior tibial artery perforator-based adipofascial flap for coverage of medial malleolus defect [Figure 2].

Commonly, authors have previously used only distally based lateral, medial and superficial sural artery-based adipofascial tissue for soft-tissue coverage. ${ }^{[3,7,8]}$ Chung et al. reported use of lateral calcaneal artery adipofascial flap for coverage of posterior heel defect. ${ }^{[6]}$ Adipofascial tissue of the anterior compartment is difficult to raise because of paucity and variable location of perforators. Using Doppler localisation of perforator, we have utilised the anterior compartment adipofascial flap for soft-tissue coverage over tibia [Figure 3] and medial malleolus. Anterior compartment tissue provides valuable tissue for reconstruction when other options are not available for soft-tissue defect coverage.
The adipofascial flap provides suitable vascular tissue for fracture site healing or salvage of the exposed bone. When adipofascial tissue is transposed over the defect, the well-vascularised fascial tissue covers the exposed bone. In our study using adipofascial flap, four of the five patients who were having fractured tibia healed satisfactorily. Apart from aesthetics and stability, important issue which should be addressed while reconstructing defect around malleolus and lower third of the leg is ease of using foot wears, ${ }^{[4]}$ clothing and socks. Use of slender adipofascial tissue for coverage has merit over other options such as fasciocutaneous flap, muscle and myocutaneous flap in this regard. In our patients, scar over the flap was satisfactorily stable, and no patient complained of recurrent ulceration or breakdown of wound in 6-month follow-up.

Adipofascial flap can be elevated with two blades, one superior and a small inferior. Both can be used to augment tissue bulk over the defect, if carefully planned [Figure 3]. Otherwise, the second inferior leaf of the flap can be used to cover the pedicle, just below the skin. Other merit of adipofascial flap is that the degree of freedom of rotation is more. This property gives an edge and should be considered to cover defects over difficult areas such as tendo-achilles and when surrounding adjacent area is scarred. In our case, there was partial loss of split-skin graft over the flap in two cases. Both the cases healed satisfactorily with repeated dressing changes.

Cosmetic disfigurement is the major disadvantage of using fasciocutaneous flap, muscle flap or free flap. When adipofascial flap is planned, primary closure of the donor site is possible after harvesting adipofascial tissue. Most studies have confirmed the superior donor-site outcome following use of adipofascial flaps [Figure 3]. In our study, there was no significant sensory loss/hyperesthesia in the skin over the donor area except in two cases who reported small anaesthetic patch over the skin flap suture line where flap of $18 \mathrm{~cm} \times 5 \mathrm{~cm}$ and $22 \mathrm{~cm} \times 6 \mathrm{~cm}$ size was harvested. Both patients recovered completely over a follow-up period of 6 months. Two patients had necrosis at donor skin flaps margin which healed by repeated dressings. Despite several merits, there are few limitations of using this flap also. It cannot be used for large soft-tissue defects, and prior Doppler localisation of perforator is mandatory. Local fasciocutaneous flap cannot be used as salvage procedure since skin flaps are already 
raised subdermally at initially steps. Post-operatively, monitoring flap viability is confounded by the presence of split-skin graft over the flap. These points should be strictly considered before planning adipofascial perforator flap.

\section{CONCLUSIONS}

Adipofascial tissue of the leg provides substantial soft tissue to cover the lower leg defects. Perforator localisation using Doppler increases the reliability of using large adipofascial tissue as flap. Furthermore, adipofascial tissue based on the perforator of anterior tibial artery can be easily harvested. Thickness of the flap may be modulated by incorporating tissues inferior and superior to the perforator and using two leaves of fascia. This is a novel technique which has not been described in the literature previously. Pliability of the adipofascial tissue confers the ability for easy moulding, increases its reach and degree of freedom which helps to reconstruct difficult soft-tissue defects particularly around malleolus and lower third of the leg. Finally, the use of adipofascial tissue results in minimal donor-site morbidity and aesthetically superior recipient site scar.

\section{Declaration of patient consent}

The authors certify that they have obtained all appropriate patient consent forms. In the form the patient(s) has/have given his/her/their consent for his/her/their images and other clinical information to be reported in the journal. The patients understand that their names and initials will not be published and due efforts will be made to conceal their identity, but anonymity cannot be guaranteed.

\section{Financial support and sponsorship}

Nil.

\section{Conflicts of interest}

There are no conflicts of interest.

\section{REFERENCES}

1. Haertsch $\mathrm{P}$. The surgical plane in the leg. $\mathrm{Br} \mathrm{J}$ Plast Surg 1981;34:464-9.

2. Lin SD, Lai CS, Chou CK, Tsai CC. Reconstruction of soft tissue defects of the lower leg with the distally based medial adipofascial flap. Br J Plast Surg 1994;47:132-7.

3. Lin SD, Lai CS, Tsai CC, Chou CK, Tsai CW. Clinical application of the distally based medial adipofascial flap for soft tissue defects on the lower half of the leg. J Trauma 1995;38:623-9.

4. Mukherjee MK, Parwaz MA, Chakravarty B, Langer V. Perforator flap: A novel method for providing skin cover to lower limb defects. Med J Armed Forces India 2012;68:328-34.

5. Suliman MT. Distally based adipofascial flaps for dorsal foot and ankle soft tissue defects. J Foot Ankle Surg 2007;46:464-9.

6. Chung MS, Baek GH, Gong HS, Rhee SH, Oh WS, Kim MB, et al. Lateral calcaneal artery adipofascial flap for reconstruction of the posterior heel of the foot. Clin Orthop Surg 2009;1:1-5.

7. Lee S, Estela CM, Burd A. The lateral distally based adipofascial flap of the lower limb. Br J Plast Surg 2001;54:303-9.

8. Parodi PC, De Biasio F, Rampino Cordaro E, Guarneri GF, Panizzo N, Riberti C, et al. Distally-based superficial sural flap: Advantages of the adipofascial over the fasciocutaneous flap. Scand J Plast Reconstr Surg Hand Surg 2010;44:37-43. 